\title{
Modifying electronic properties of ICBA through chemical substitutions for solar cell applications
}

\author{
Eliezer Fernando Oliveira ${ }^{1} \cdot$ Lucas Castorino Silva $^{2} \cdot$ Francisco Carlos Lavarda $^{1,3}$
}

Received: 1 December 2016 / Accepted: 25 January 2017 / Published online: 10 February 2017

(C) Springer Science+Business Media New York 2017

\begin{abstract}
Fullerene derivatives are the most widely used type of acceptor material in the organic solar cells (OSCs) active layers, but there are still some problems to be overcome, such as increased solubility and adjustment of the frontier electronic levels for a better combination with the donor materials in the active layer. Chemical modification of the materials already employed in active layers is an interesting way to vary the electronic properties in order to find new materials, because it is possible, in principle, to tune the intrinsic properties of the material aiming to improve the solar cell efficiency. Thus, we studied theoretically the effect caused by chemical substitutions on the electronic properties of the ICBA, one of the fullerene derivatives employed in OSCs. Geometry optimizations and electronic structure data were obtained by DFT/PBE/6-311G(d,p) calculations for 13 ICBA derivatives. We show that by chemical substitutions of ICBA, it is possible to modify the energies of the frontier electronic levels, increase the solubility, and find new derivatives that show
\end{abstract}

Electronic supplementary material The online version of this article (doi:10.1007/s11224-017-0916-0) contains supplementary material, which is available to authorized users.

Eliezer Fernando Oliveira

eliezer@fc.unesp.br

1 UNESP - Univ Estadual Paulista, POSMAT - Programa de Pós-Graduação em Ciência e Tecnologia de Materiais, Av. Eng. Luiz Edmundo Carrijo Coube 14-01, Bauru, SP 17033-360, Brazil

2 UNESP - Univ Estadual Paulista, Graduação em Física, FC Faculdade de Ciências, Av. Eng. Luiz Edmundo Carrijo Coube 14-01, Bauru, SP 17033-360, Brazil

3 DF-FC, UNESP - Univ Estadual Paulista, Av. Eng. Luiz Edmundo Carrijo Coube 14-01, Bauru, SP 17033-360, Brazil improvements in open circuit voltage and morphology of the active layer, potentially bringing better efficiency for OSCs.

Keywords Computational modeling $\cdot$ Engineering of electronic properties $\cdot$ Chemical modifications $\cdot$ ICBA . Organic solar cells

\section{Introduction}

The most common electron acceptor for bulk heterojunctions organic solar cells is the phenyl- $\mathrm{C}_{61}$-butyric-acid-methyl-ester (PCBM) [1-4]. Looking for better electron acceptor materials, the indene- $\mathrm{C}_{60}$ bisadduct (ICBA) was proposed [5] (see Fig. 1) and has shown to be a promising substitute for the PCBM, once (i) it presents an easier synthesis [5] and (ii) higher open circuit voltages $\left(\mathrm{V}_{\mathrm{OC}}\right)$ and electric currents in the devices were achieved in active layers with common electron donor materials, such as poly(3-hexylthiophene) (P3HT) $[6,7]$. Despite the advantages of ICBA, lower values for fill factor (FF) are observed compared with those using PCBM, probably due to a lower solubility $[5,6,8]$.

We showed previously for conjugated polymers that the use of chemical substitutions is an efficient tool to modify the intrinsic properties of the materials, since it was possible to obtain new derivatives with varying levels of solubility, better ionization potentials, and electronic levels close to what is considered ideal in the literature [9-12]. In the case of fullerene derivatives, it is still not clear if there is the possibility to significantly vary the electronic properties by chemical substitutions [13]. Thus, as the ICBA is a promising material for use in active layers of OSC and still has some deficiencies regarding the most used PCBM, in this study, we evaluated the effects of chemical substitutions on the electronic properties of the ICBA. 


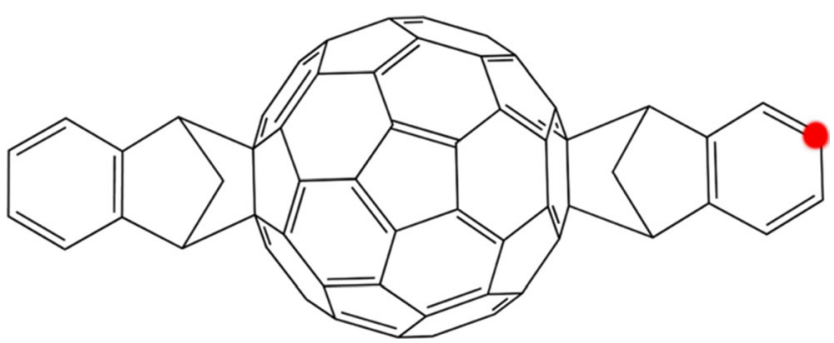

Fig. 1 Structure of ICBA. The red point indicates the position where the substitutions were performed

In this work, we studied theoretically 13 ICBA derivatives in which we performed chemical substitutions in one of its indene groups. In the first part of the work, we studied the effects caused in the electronic structure, in which was possible to find new promising derivatives. The most interesting result was that the chemical substitutions were able to significantly modify the dipole moment of the ICBA, which favors a good morphology and charge transport in the active layer. The largest dipole moments were obtained for the derivatives substituted with groups with strong electron-releasing or electron-withdrawing character.

In the second part of the work, we compared the energies of the frontier electronic levels of P3HT and polythieno[3,4-b]thiophene-co-benzodithiophene (PTB7) [10, 14] as electron donor materials with ICBA derivatives as electron acceptor materials. Overall, it is not predicted problems in the exciton dissociation and recombination in these possible active layers. Also, the calculations indicate that some ICBA derivatives could have a higher $\mathrm{V}_{\mathrm{OC}}$ in the device than the active layers using ICBA or PCBM; this suggests that the solar cell efficiency tends to increase using these ICBA derivatives together with P3HT or PTB7.

\section{Materials and methods}

All geometry optimizations were performed using density functional theory (DFT) due to its broad and successful employment in organic materials studies [15-19] and even coupled with quantitative structure-properties relationship studies $[20,21]$. However, for good reliability of the results obtained by DFT, we must first choose the correlation and exchange functional that best suits to the system studied [16, 22]. To determine which functional would be used in our calculations, we conducted a preliminary study for the ICBA, performing geometry optimizations with some of the most commonly used functional in the literature, among them hybrids with different amounts of Hartree-Fock exact exchange as well as those that include corrections for longrange interactions; the choice of the functional will be guided by that one that presents the best predictions for the electronic properties of ICBA compared to the experimental data. We tested the functionals B3LYP [23, 24], CAM-B3LYP [25], BHLYP [24], M06HF [26], X3LYP [27], and PBE [28], employing the basis set functions $6-311 \mathrm{G}(\mathrm{d}, \mathrm{p})$ and the software GAUSSIAN09 [29]. Geometry optimizations were performed for various initial structures, to assess all possible conformations and to ensure that only those of lowest energy would be chosen for the study. The equilibrium geometries were confirmed by vibrational spectrum calculations since no imaginary frequencies were found. Table 1 presents the results obtained for each functional tested and the deviation obtained in relation to the experimental data. We analyzed the energies of the highest occupied and the lowest unoccupied molecular orbitals ( $\mathrm{E}_{\mathrm{HOMO}}$ and $\mathrm{E}_{\mathrm{LUMO}}$, respectively). As can be seen, the smallest deviations obtained for both $\mathrm{E}_{\mathrm{HOMO}}$ and $\mathrm{E}_{\mathrm{LUMO}}$ were with the PBE functional (below 10\%). This result is in agreement with previous studies, where the PBE functional has shown good results for fullerene derivatives in comparison with experimental data [30-33]. Thus, we decided to conduct our studies using the DFT/PBE/6-311G(d,p) methodology.

After determining the calculation methodology that would be adopted, we performed chemical substitutions in the ICBA in one of the indene groups that are inserted into the fullerene in order to remove the system symmetry. We modified the most extreme position, which is highlighted in Fig. 1. The following substituents were chosen: chlorine $(\mathrm{Cl})$, bromine (Br), fluorine $(\mathrm{F})$, hydroxy $(\mathrm{OH})$, cyano $(\mathrm{CN})$, amino $\left(\mathrm{NH}_{2}\right)$, methyltio $\left(\mathrm{SCH}_{3}\right)$, trifluoromethyl $\left(\mathrm{CF}_{3}\right)$, methyl $\left(\mathrm{CH}_{3}\right)$, dimethylamino $\left(\mathrm{N}\left(\mathrm{CH}_{3}\right)_{2}\right)$, metoxy $\left(\mathrm{OCH}_{3}\right)$, carboxy $(\mathrm{COOH})$, and ethenyl $\left(\mathrm{CH}=\mathrm{CH}_{2}\right)$. It is interesting to note that the selected substituents have different effects and intensities of charge releasing/withdrawing, which is important to make a comprehensive analysis of the influences of the substituents on the electronic properties of the ICBA. We also tested more than one chemical substitution in the indene group. However, the results were very similar to that obtained with only one substitution; based on this fact, we continued the study with only one chemical modification.

\section{Results and discussion}

\section{Electronic properties of ICBA derivatives}

We present in Table S1 in the Electronic Supplementary Material the theoretical results for $\mathrm{E}_{\mathrm{HOMO}}$ and $\mathrm{E}_{\mathrm{LUMO}}$ of ICBA and its derivatives. As we know that there is a deviation in the theoretical results for the ICBA, the derivatives would have a double deviation, i.e., a deviation in relation to the theoretical data of ICBA which already has a deviation from the experimental data. To let our analysis be more realistic, we decided to insert scale factors (SF) on the theoretical data of ICBA derivatives. So, based in the experimental data, we 
Table 1 Electronic structure data of ICBA from some different functionals

\begin{tabular}{lllll}
\hline ICBA & $\mathrm{E}_{\text {HOMO }}(\mathrm{eV})$ & $\mathrm{E}_{\text {HOMO }}$ Deviation $(\%)$ & $\mathrm{E}_{\mathrm{LUMO}}(\mathrm{eV})$ & $\mathrm{E}_{\mathrm{LUMO}}$ Deviation (\%) \\
\hline Experimental [5, 34] & -5.60 & - & -3.70 & - \\
B3LYP & -4.49 & 19.82 & -3.82 & 3.34 \\
CAM-B3LYP & -6.16 & -10.07 & -2.27 & 38.63 \\
BHLYP & -5.76 & -2.88 & -2.39 & 35.22 \\
M06HF & -7.82 & -39.71 & -1.88 & 49.31 \\
X3LYP & -4.98 & 10.97 & -3.18 & 13.95 \\
PBE & -5.22 & 6.81 & -3.83 & -1.04 \\
\hline
\end{tabular}

multiply the theoretical values of $\mathrm{E}_{\mathrm{HOMO}}$ and $\mathrm{E}_{\mathrm{LUMO}}$ of the ICBA derivatives by the following SF: $\mathrm{SF}_{\mathrm{HOMO}}=(5.6 / 5.2)$ and $\mathrm{SF}_{\mathrm{LUMO}}=(3.7 / 3.8)$. The data of the electronic structure recalculated for ICBA and its derivatives are shown in Fig. 2; these recalculated data are also reproduced in Table S2 of the Electronic Supplementary Material. In order to make some comparisons in our analysis, we also inserted in Fig. 2 the energies $\mathrm{E}_{\mathrm{HOMO}}$ and $\mathrm{E}_{\mathrm{LUMO}}$ of PCBM, which are, respectively, -6.0 and $-4.2 \mathrm{eV}$ [35]. As we can see, the chemical substitutions were able to change the electronic properties of ICBA, with percentage variations between -4.0 and $2.5 \%$ for $\mathrm{E}_{\mathrm{LUMO}}$ and between -1.3 and $12.0 \%$ for $\mathrm{E}_{\mathrm{HOMO}}$. Although it was not observed large changes due to chemical substitutions, it is worth to point here that a significant impact on solar cell efficiency parameters can be predicted, as discussed in the following section.

Half of the ICBA derivatives showed an $\mathrm{E}_{\mathrm{HOMO}}$ higher than that observed for the pure ICBA, being the most pronounced difference for ICBA-N $\left(\mathrm{CH}_{3}\right)_{2}, 12 \%$ higher; the lowest $\mathrm{E}_{\mathrm{HOMO}}$ was found for P3HT-CN, 3\% lower. In relation to $\mathrm{E}_{\mathrm{LUMO}}$, smaller variations were obtained compared with those obtained for the $\mathrm{E}_{\mathrm{HOMO}}$. Six ICBA derivatives presented an increase in $\mathrm{E}_{\mathrm{LUMO}}$, being the highest observed for ICBA$\mathrm{N}\left(\mathrm{CH}_{3}\right)_{2}, 2.4 \%$ higher; ICBA-CN had the lowest $\mathrm{E}_{\mathrm{LUMO}}$, approximately $4 \%$ lower. Considering a bulk heterojunction, the higher the $\mathrm{E}_{\mathrm{LUMO}}$ of the acceptor material, the better the $\mathrm{V}_{\mathrm{OC}}$ of the device [35-37]; that is why the use of ICBA has brought significant improvements in the solar cell performance [6, 7], once the ICBA's $\mathrm{E}_{\mathrm{LUMO}}$ is higher than that of PCBM (see Fig. 2). For ICBA derivatives, six of them showed an increase in $\mathrm{E}_{\mathrm{LUMO}}$ and would tend to have a higher $\mathrm{V}_{\mathrm{OC}}$ in the device than the ICBA or PCBM. However, we have to be careful with the $\mathrm{E}_{\mathrm{HOMO}}$ of the electron acceptor material, because depending on its value relative to $\mathrm{E}_{\mathrm{HOMO}}$ of the electron donor material, problems with dissociation and/or recombination of excitons could arise [9, 37]. A more detailed analysis regarding these issues will be made further on.

We can also evaluate the oxidation stability of the studied materials when exposed to the environment. As the acceptor material in the solar cell's active layer receives the electrons of the donor material in the LUMO orbital, it is necessary to have a $E_{\text {LUMO }}$ approximately equal to or less than $-4.0 \mathrm{eV}$ to ensure the stability to oxidation [38]. According to this criterion, the ICBA is not as stable to oxidation as one would like, because it has a $\mathrm{E}_{\mathrm{LUMO}}$ of $-3.7 \mathrm{eV}$. PCBM is more stable than ICBA with a $E_{\text {LUMO }}$ of $-4.2 \mathrm{eV}$. Our results showed that the ICBA derivatives still present values for $\mathrm{E}_{\mathrm{LUMO}}$ above the limit of $-4.0 \mathrm{eV}$, but our calculations suggest that seven of them are more stable to oxidation than ICBA (substituted with $\mathrm{Cl}, \mathrm{Br}, \mathrm{F}$, $\mathrm{CN}, \mathrm{CF}_{3}, \mathrm{COOH}$, and $\mathrm{CH}=\mathrm{CH}_{2}$ ). ICBA-Cl, ICBA-Br, ICBA$\mathrm{CN}$, and $\mathrm{ICBA}-\mathrm{CF}_{3}$ are the best derivatives, with a $\mathrm{E}_{\mathrm{LUMO}}$ around $-3.8 \mathrm{eV}$.

As for the energy gap Eg between the LUMO and HOMO orbitals $\left(\mathrm{E}_{\mathrm{LUMO}}-\mathrm{E}_{\mathrm{HOMO}}\right)$, the majority of derivatives have
Fig. 2 Results obtained for $\mathrm{E}_{\mathrm{HOMO}}$ and $\mathrm{E}_{\mathrm{LUMO}}$ of ICBA and its derivatives. The data for PCBM was also inserted. The dashed lines indicate the position of the ICBA values

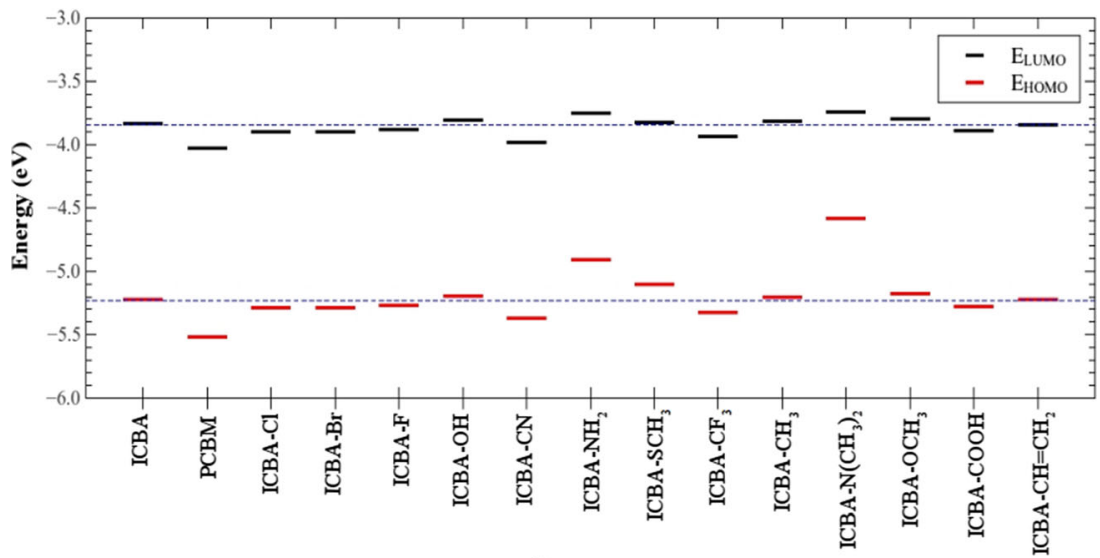

Structure 
values around $1.9 \mathrm{eV}$, equal to that for the ICBA, except the derivatives ICBA-N $\left(\mathrm{CH}_{3}\right)_{2}$, ICBA-SH$H_{3}$, and ICBA-NH $\mathrm{I}_{2}$, with an Eg of 1.16, 1.76 and $1.58 \mathrm{eV}$, respectively; PCBM has an $\mathrm{Eg}$ of $1.8 \mathrm{eV}$, narrower than that for the ICBA and most of its derivatives. The Eg of the acceptor material is also important for the solar cell, because once they are exposed to the solar spectrum, their excited electrons can also contribute to the photocurrent $[37,39]$. For this fact, we note that the derivatives ICBA-N $\left(\mathrm{CH}_{3}\right)_{2}$, ICBA-SH$H_{3}$, and ICBA- $\mathrm{NH}_{2}$ will be better than the ICBA and PCBM, since the photons of lower energy may be absorbed so that, together with the donor material, a wider range of the solar spectrum can be used.

It is known from literature that the variation of $\mathrm{E}_{\mathrm{HOMO}}$ and $\mathrm{E}_{\mathrm{LUMO}}$, and consequently the $\mathrm{Eg}$, is closely related to the electron-releasing or electron-withdrawing ability of the substituent $[9,10,37]$ : electron-withdrawing substituents tend to stabilize the energies of the frontier orbitals, whereas electronreleasing substituents bring destabilization. For the ICBA dervatives, we note that this trend is confirmed, but the variations obtained were not as significant as expected. This happens because the substitutions in fullerene derivatives are usually made at locations far from the electron density of the frontier orbitals, which are located completely in the fullerene, as can be seen in Fig. 3a, where the HOMO and LUMO orbitals of the ICBA are presented. In the case of polymers, for example, it was verified in previous studies that the variations in the electronic properties due to chemical substitutions are in fact much more significant $[9,10,12]$, once the substituents can interact directly with the electron density of the frontier orbitals, causing major changes in $\mathrm{E}_{\mathrm{HOMO}}$ and $\mathrm{E}_{\mathrm{LUMO}}$ energies. We also noted in the ICBA derivatives, that substituents with strong electron-releasing character (e.g., $\mathrm{NH}_{2}$ and $\left.\mathrm{N}\left(\mathrm{CH}_{3}\right)_{2}\right)$ are able to displace the HOMO orbital region to the indene group (see the frontier orbitals in Fig. 3b, c), but without major changes in the LUMO. In the case of substituents with a strong electron-withdrawing character, as the $\mathrm{CN}$ substituent, the frontier orbitals remain concentrated in the fullerene, as we can see in Fig. 3d.

While chemical modifications in the ICBA bring only slight changes in $\mathrm{E}_{\mathrm{HOMO}}$ and $\mathrm{E}_{\mathrm{LUMO}}$ energies, we realize that for the dipole moment (DM) they produce a considerable effect. It is known that the DM of the materials used in the active layer of the solar cell influences the morphology and the solubility of the material (and consequently the FF), as well as in the charge transfer between the donor and the acceptor materials $[40,41]$. Then, the larger the DM, the better these properties will be. Because of the high symmetry of the ICBA, it is expected that it has a low DM, a fact that influences in its low solubility verified experimentally $[42,43]$. Figure 4 shows the theoretical DM obtained for ICBA and its derivatives. We also calculated the theoretical DM of the PCBM with the same methodology employed for the ICBA, as described in section 2; the value was also inserted in Fig. 4. As we can see, indeed the ICBA has a low DM, close to 0 Debye; in the case of ICBA derivatives, as expected, all modify the symmetry and the charge distribution in the system inducing a larger DM. The DM of the derivative ICBA-CN was the largest of all, suggesting to be a good candidate to be used in solar cells to improve the morphology and charge transfer. We note that PCBM also has a DM larger than that for the ICBA and that is why it is observed in the literature that the best morphologies for the active layers are achieved using PCBM [44]. Overall, the structures that have been inserted substituents with strong electron-releasing or electron-withdrawing character showed the largest DM of all the substituents employed.

\section{Analysis of the solar cell performance parameters for active layer that could employ P3HT or PTB7 combined with ICBA derivatives}

To evaluate the real usefulness of the ICBA derivatives, it is interesting to make an analysis of how would be its performance in active layers of solar cells. In this section we will assess whether it could be attractive to use some ICBA derivatives in combination with $\mathrm{P} 3 \mathrm{HT}$ or polythieno[3,4-b]-thiophene-co-benzodithiophene (PTB7), the electron donor materials most employed in solar cells [45]; this step is important, because it is known that the energies of the frontier electronic levels of the acceptor (A) and the donor (D) materials have a direct correlation with the parameters of efficiency of organic solar cells [37].

Figure 5 shows an energy scheme of the frontier electronic levels of the donor and acceptor materials in the active layer of the solar cell. Photons absorbed by the donor material generate
Fig. 3 Kohn-Sham orbital representation (isovalue surface of $0.015 \mathrm{au}$ ) of LUMO (up) and $\mathrm{HOMO}($ down) for a ICBA, $\mathbf{b}$ ICBA-NH2, c ICBA-N(CH3 )2, and $\mathbf{d}$ ICBA-CN
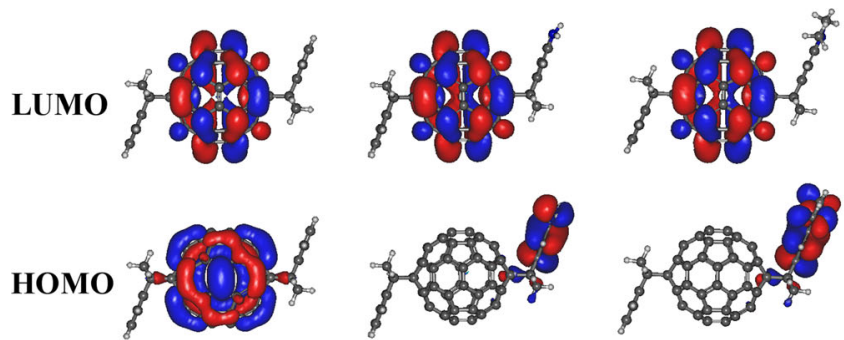

(b)

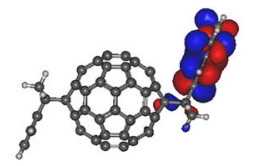

(c)
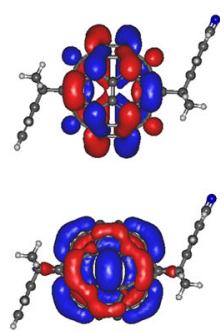

(d) 
Fig. 4 Dipole moment (in Debye) of ICBA and its derivatives and PCBM. The dashed lines indicate the ICBA value level

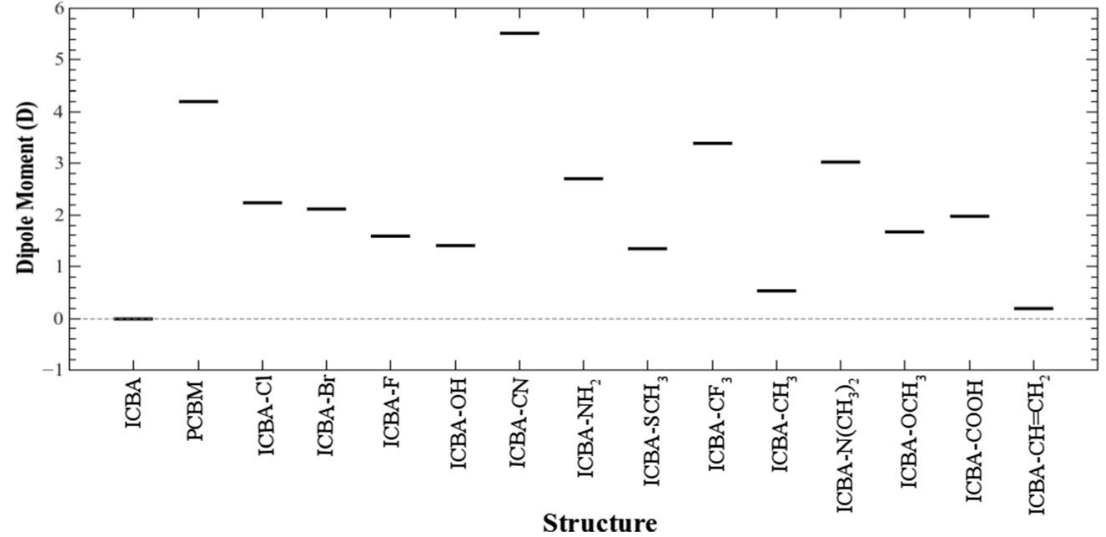

Fig. 6 shows the results for $\Delta \mathrm{E}_{\mathrm{LL}}, \Delta \mathrm{E}_{\mathrm{HL}}$, and $\Delta \mathrm{E}_{\mathrm{HH}}$ in the combinations performed with ICBA derivatives as electron acceptor and P3HT and PTB7 as electron donors (these data are also shown in Tables S3 and S4 in the Electronic Supplementary Material); combinations with PCBM are also presented. The values for $\mathrm{E}_{\mathrm{HOMO}}$ and $\mathrm{E}_{\mathrm{LUMO}}$ of P3HT and PTB7 employed in these analyzes were, respectively, -5.1 and $-2.9 \mathrm{eV}$ [47] and -5.2 and $-3.3 \mathrm{eV}$ [48]. The parameters $\Delta \mathrm{E}_{\mathrm{LL}}$ and $\Delta \mathrm{E}_{\mathrm{HH}}$ will be compared with the $\mathrm{Eb}$ of P3HT and PTB7, which are approximately 0.3 and $0.2 \mathrm{eV}[49,50]$, respectively.

As can be seen in Fig. 6a, b, with exception of the derivatives ICBA-NH$H_{2}$ and ICBA-N $\left(\mathrm{CH}_{3}\right)_{2}$, the parameters $\Delta \mathrm{E}_{\mathrm{LL}}$ and $\Delta \mathrm{E}_{\mathrm{HH}}$ of the majority of the cases studied had the $\mathrm{Eb}$ higher than that of P3HT and PTB7, indicating that in general there will be no problems related to exciton dissociation and recombination in the active layer. The derivatives substituted with $\mathrm{NH}_{2}$ and $\mathrm{N}\left(\mathrm{CH}_{3}\right)_{2}$, which are those with strong electronreleasing character, have $\Delta \mathrm{E}_{\mathrm{HH}}<\mathrm{Eb}$ due to $\mathrm{E}_{\mathrm{HOMO}}$ values very close to or above those of P3HT and PTB7. The values obtained for the parameters $\Delta \mathrm{E}_{\mathrm{HL}}$ indicate that all ICBA derivatives studied would tend to have a higher $\mathrm{V}_{\mathrm{OC}}$ in the device than the PCBM in combination with P3HT or PTB7; however, only the derivatives substituted with $\mathrm{OH}, \mathrm{NH}_{2}$, $\mathrm{SCH}_{3}, \mathrm{CH}_{3}, \mathrm{~N}\left(\mathrm{CH}_{3}\right)_{2}$, and $\mathrm{OCH}_{3}$ would present a higher $\mathrm{V}_{\mathrm{OC}}$ than that obtained with the ICBA. As the derivatives ICBA-NH $\mathrm{N}_{2}$ and ICBA-N $\left(\mathrm{CH}_{3}\right)_{2}$ presented problems in the parameter $\Delta \mathrm{E}_{\mathrm{HH}}$, to enhance the $\mathrm{V}_{\mathrm{OC}}$ without causing problems in the exciton dissociation and recombination, the best derivatives to be employed would be the ICBA-OH, ICBA$\mathrm{SCH}_{3}, \mathrm{ICBA}-\mathrm{CH}_{3}$, and ICBA-OCH $\mathrm{I}_{3}$.

If we look again in the results shown in Fig. 4, we note that the cases that had the best compromise with the parameters $\Delta \mathrm{E}_{\mathrm{LL}}, \Delta \mathrm{E}_{\mathrm{HL}}$, and $\Delta \mathrm{E}_{\mathrm{HH}}$ also had a dipole moment larger than that for ICBA; thus, these materials would tend to have better morphologies (facilitating the charge transport) than ICBA, favoring an increasing of the solar cell efficiency when combined with P3HT or PTB7. However, there are others ICBA derivatives with larger dipole moments that also would tend to

Fig. 5 Energy levels sketch for acceptor and donor materials and the parameters that influence the efficiency of the organic solar cell 
Fig. 6 Obtained values for $\Delta \mathrm{E}_{\mathrm{HH}}, \Delta \mathrm{E}_{\mathrm{HL}}$, and $\mathrm{E}_{\mathrm{LL}}$ of ICBA derivatives and $\mathrm{PCBM}$ in combination with a $\mathrm{P} 3 \mathrm{HT}$ and $\mathbf{b}$ $\mathrm{PTB} 7$. The dashed lines indicate the P3HT/ICBA and PTB7/ICBA values level. $\Delta \mathrm{E}_{\mathrm{HH}}$ and $\Delta \mathrm{E}_{\mathrm{LL}}$ should be greater than $\mathrm{Eb}$

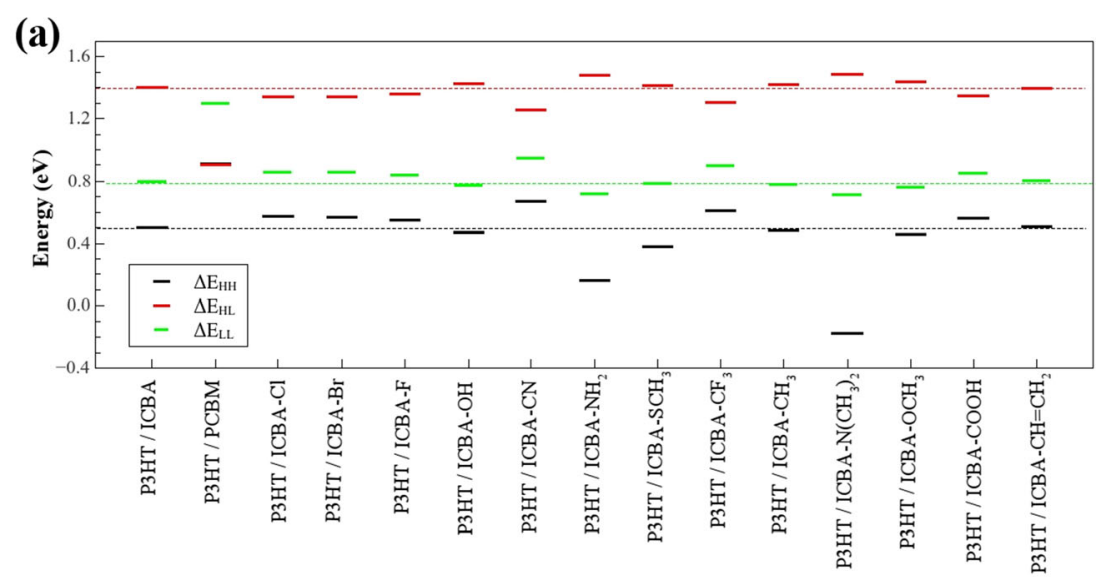

Donor-Acceptor Combination

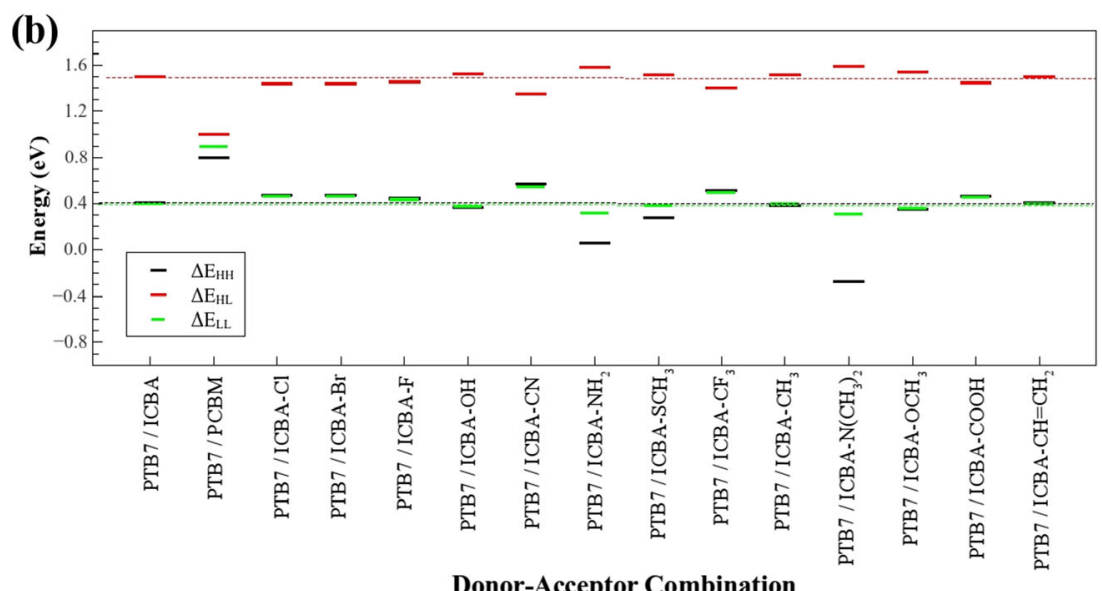

have a decreased $\mathrm{V}_{\mathrm{OC}}$ than that for the ICBA; this is the case of the ICBA-CN, that presented the largest dipole moment compared to other derivatives, but with a smaller $\Delta \mathrm{E}_{\mathrm{HL}}$ than ICBA. These derivatives could be used in solar cells due to the opportunity to get better morphologies, but already knowing in advance that a lower efficiency would be achieved in relation to ICBA when combined with P3HT or PTB7.

It is worth emphasizing that in this section we made estimates for the parameters that have a direct influence in solar cell efficiency when we are using ICBA derivatives in combination with $\mathrm{P} 3 \mathrm{HT}$ or PTB7 as electron donor material in the active layer. If the same analyzes were performed in combination with other electron donor materials, possibly other ICBA derivatives could draw attention to the use of the active layer.

\section{Conclusions}

We studied theoretically the electronic structure of 13 new derivatives of ICBA for applications in active layers of solar cells in which chemical substitutions were performed in one of the indene group. The dipole moment of the ICBA was significantly modified, which favors a good morphology and charge transport in the active layer, without losses in the electronic properties. The largest dipole moments were obtained for the derivatives substituted with groups with strong electron-releasing or electron-withdrawing character, for example, $\mathrm{CN}, \mathrm{NH}_{2}$, and $\mathrm{N}\left(\mathrm{CH}_{3}\right)_{2}$.

In active layers that combine $\mathrm{P} 3 \mathrm{HT}$ or PTB7 as donor material with ICBA derivatives, it was verified that overall there would be no problems in the exciton dissociation and recombination; this happened because the parameters $\Delta \mathrm{E}_{\mathrm{HH}}$ and $\Delta \mathrm{E}_{\mathrm{LL}}$ were higher or near to the Eb of P3HT and PTB7, except for the derivatives ICBA-NH$H_{2}$ and ICBA-N $\left(\mathrm{CH}_{3}\right)_{2}$. Furthermore, the derivatives ICBA-OH, ICBA-SCH 3 , ICBA- $\mathrm{CH}_{3}$, and ICBA-OCH $\mathrm{OH}_{3}$ would tend to have a higher $\mathrm{V}_{\mathrm{OC}}$ in the device than the active layers using ICBA and PCBM, since they had the largest $\Delta \mathrm{E}_{\mathrm{HL}}$; these derivatives could be indicated in order to increase the solar cell efficiency. If we perform the same analysis using other donor material, possibly others ICBA derivatives could be feasible for use.

In our opinion, these ICBA derivatives can have a great impact in OSC performance since our calculations suggest that they can enhance the morphology and the open circuit voltage, both crucial parameters for solar to electric energy conversion efficiency. 
Acknowledgments We would like to thank the Brazilian agency FAPESP (proc. 2012/21983-0 and 2014/20410-1) for financial support. This research was also supported by resources supplied by the Center for Scientific Computing (NCC/GridUNESP) of the São Paulo State University (UNESP).

\section{References}

1. Chi D, Qu S, Wang Z, Wang J (2014) High efficiency P3HT:PCBM solar cells with an inserted PCBM layer. J Mater Chem C 2:4383

2. Dang MT, Wantz G, Bejbouji H, Urien M, Dautel OJ, Vignau L, et al. (2011) Polymeric solar cells based on P3HT:PCBM: role of the casting solvent. Sol Energy Mater Sol Cells 95:3408-3418

3. González DM, Körstgens V, Yao Y, Song L, Santoro G, Roth SV, et al. (2015) Improved power conversion efficiency of P3HT: PCBM organic solar cells by strong spin-orbit coupling-induced delayed fluorescence. Adv Energy Mater 5:1401770

4. Ng A, Liu X, Jim WY, Djurišić AB, Lo KC, Li SY, et al. (2014) P3HT : PCBM solar cells-the choice of source material. J Appl Polym Sci 131(39776):1-9

5. He Y, Chen H-Y, Hou J, Li Y (2010) Indene- $\mathrm{C}_{60}$ bisadduct: a new acceptor for high-performance polymer solar cells. J Am Chem Soc 132:1377-1382

6. Cheng P, Li Y, Zhan X (2014) Efficient ternary blend polymer solar cells with indene- $\mathrm{C}_{60}$ bisadduct as an electron-cascade acceptor. Energy Environ Sci 7:2005

7. Chen Q, Mao L, Li Y, Kong T, Wu N, Ma C, et al. (2015) Quantitative operando visualization of the energy band depth profile in solar cells. Nat Commun 6:7745

8. Zhuang T, Wang X-F, Sano T, Hong Z, Yang Y, Kido J (2013) Fullerene derivatives as electron donor for organic photovoltaic cells. Appl Phys Lett 103:203301

9. Oliveira EF, Lavarda FC (2014) Molecular design of new P3HT derivatives: adjusting electronic energy levels for blends with PCBM. Mater Chem Phys 148:923-932

10. Roldao JC, Oliveira EF, Lavarda FC (2016) Electronic structure of polythieno[3,4-b]-thiophene-co-benzodithiophene (PTB7) derivatives for organic solar cell applications. Org Electron 33:246-252

11. Oliveira EF, Lavarda FC (2016) Copolymers with similar comonomers: tuning frontier orbital energies for application in organic solar cells. Polym Eng Sci 56:479-487

12. de Oliveira EF, Camilo-Jr A, da Silva-Filho LC, Lavarda FC (2013) Effect of chemical modifications on the electronic structure of poly(3-hexylthiophene). J Polym Sci Part B Polym Phys 51:842846

13. Kroon R, Lenes M, Hummelen JC, Blom PWM, de Boer B (2008) Small Bandgap Polymers for Organic Solar Cells (Polymer Material Development in the Last 5 Years). Polym Rev. 48:531582

14. Lu L, Yu L (2014) Understanding low bandgap polymer PTB7 and optimizing polymer solar cells based on it. Adv Mater 26:44134430

15. Körzdörfer T, Brédas J-L (2014) Organic electronic materials: recent advances in the DFT description of the ground and excited states using tuned range-separated hybrid functionals. Acc Chem Res 47:3284-3291

16. Oliveira EF, Roldao JC, Milián-Medina B, Lavarda FC, Gierschner $\mathrm{J}$ (2016) Calculation of low bandgap homopolymers: comparison of TD-DFT methods with experimental oligomer series. Chem Phys Lett 645:169-173

17. Jain A, Shin Y, Persson KA (2016) Computational predictions of energy materials using density functional theory. Nat Rev Mater 1: 15004
18. Zade SS, Zamoshchik N, Bendikov M (2011) From short conjugated oligomers to conjugated polymers. Lessons from studies on long conjugated oligomers. Acc Chem Res 44:14-24

19. Al-Sehemi AG, Al-Melfi MAM, Irfan A (2013) Electronic, optical, and charge transfer properties of donor-bridge-acceptor hydrazone sensitizers. Struct Chem 24:499-506

20. Kar S, Sizochenko N, Ahmed L, Batista VS, Leszczynski J (2016) Quantitative structure-property relationship model leading to virtual screening of fullerene derivatives: exploring structural attributes critical for Photoconversion efficiency of polymer solar cell acceptors. Nano Energy 26:677-691

21. Kar S, Roy J, Leszczynska D, Leszczynski J (2017) Power conversion efficiency of arylamine organic dyes for dye-sensitized solar cells (DSSCs) explicit to cobalt electrolyte: understanding the structural attributes using a direct QSPR approach. Computation. doi:10. 3390/computation5010002

22. Laird BB, Ross RB, Ziegler T (1996) Chemical applications of density-functional theory. American Chemical Society, Washington, DC

23. Becke AD (1993) A new mixing of Hartree-Fock and local densityfunctional theories. J Chem Phys 98:1372-1377

24. Becke AD (1993) Density-functional thermochemistry. III. The role of exact exchange. J Chem Phys 98:5648-5652

25. Yanai T, Tew DP, Handy NC (2004) A new hybrid exchange-correlation functional using the Coulomb-attenuating method (CAMB3LYP). Chem Phys Lett 393:51-57

26. Grimme S, Ehrlich S, Goerigk L (2011) Effect of the damping function in dispersion corrected density functional theory. J Comput Chem 32:1456-1465

27. Xu X, Zhang Q, Muller RP, Goddard WA (2005) An extended hybrid density functional (X3LYP) with improved descriptions of nonbond interactions and thermodynamic properties of molecular systems. J Chem Phys 122:14105

28. Paier J, Hirschl R, Marsman M, Kresse G (2005) The PerdewBurke-Ernzerhof exchange-correlation functional applied to the G2-1 test set using a plane-wave basis set. J Chem Phys 122: 234102

29. Frisch MJ, Trucks GW, Schlegel HB, Scuseria GE, Robb MA, Cheeseman JR, et al (2009) Gaussian09, Revision D. 01, Gaussian. Inc., Wallingford, CT

30. Zhang X, Li X-D (2014) Effect of the position of substitution on the electronic properties of nitrophenyl derivatives of fulleropyrrolidines: fundamental understanding toward raising LUMO energy of fullerene electron-acceptor. Chin Chem Lett 25: 501-504

31. Ferreira RM, Batagin-Neto A, Lavarda FC (2015) Modeling of open-circuit voltage of phenyl C61-butyric acid methyl Ester-like based bulk-heterojunction solar cells. J Nanosci Nanotechnol 15: 9960-9965

32. Zhang X, Ma L-X, Li X-D (2014) Establishment of a linear correlation between the LUMO levels of fullerenes and the Hammett constants of substituents installed: an experimental and theoretical study. Synth Met 198:357-360

33. Krasnokutski SA, Kuhn M, Kaiser A, Mauracher A, Renzler M, Bohme DK, et al. (2016) Building carbon bridges on and between fullerenes in helium nanodroplets. J Phys Chem Lett 7(8):1440 1445

34. Matsuo Y (2012) Design Concept for High-LUMO-level Fullerene Electron-acceptors for Organic Solar Cells. Chem Lett 41:754-759

35. Zhou H, Yang L, You W (2012) Rational Design of High Performance Conjugated Polymers for Organic Solar Cells. Macromolecules 45:607-632

36. Li G, Zhu R, Yang Y (2012) Polymer solar cells. Nat Photonics 6: 153-161 
37. Li Y (2012) Molecular Design of Photovoltaic Materials for Polymer Solar Cells: Toward Suitable Electronic Energy Levels and Broad Absorption. Acc Chem Res 45:723-733

38. Takimiya K, Osaka I, Nakano M (2014) $\pi$-Building Blocks for Organic Electronics: Revaluation of "Inductive" and "Resonance" Effects of $\pi$-Electron Deficient Units. Chem Mater 26:587-593

39. Nicolaidis NC, Routley BS, Holdsworth JL, Belcher WJ, Zhou X, Dastoor PC (2011) Fullerene Contribution to Photocurrent Generation in Organic Photovoltaic Cells. J Phys Chem C 115: 7801-7805

40. Carsten B, Szarko JM, Son HJ, Wang W, Lu L, He F, et al. (2011)Examining the Effect of the Dipole Moment on Charge Separation in Donor-Acceptor Polymers for Organic Photovoltaic Applications. J Am Chem Soc 133:20468-20475

41. Kumar R, Khan S, Gupta N, Naqvi S, Gaurava K, Sharma C, Kumar M, Kumar P, Chand S (2016) Fullerene grafted graphene oxide with effective charge transfer interactions. Carbon 107:765-773

42. Chen H, Hsiao Y-C, Hu B, Dadmun M (2014) Control of morphology and function of low band gap polymer-bis-fullerene mixed heterojunctions in organic photovoltaics with selective solvent vapor annealing. J Mater Chem A. 2:9883

43. Choy WCH (2013) Organic solar cells: materials and device physics. Springer, London
44. Lin Y-H, Tsai Y-T, Wu C-C, Tsai C-H, Chiang C-H, Hsu H-F, et al. (2012) Comparative study of spectral and morphological properties of blends of P3HT with PCBM and ICBA. Org Electron 13:2333-2341

45. Cho S, Rolczynski BS, Xu T, Yu L, Chen LX (2015) Solution phase exciton diffusion dynamics of a charge-transfer copolymer PTB7 and a Homopolymer P3HT. J Phys Chem B 119: $7447-7456$

46. Bredas J-L (2014) Mind the gap! Mater Horiz 1:17-19

47. Ameri T, Min J, Li N, Machui F, Baran D, Forster M, et al. (2012) Performance enhancement of the P3HT/PCBM solar cells through NIR sensitization using a small-bandgap polymer. Adv Energy Mater 2:1198-1202

48. Liang Y, Xu Z, Xia J, Tsai S-T, Wu Y, Li G, et al. (2010) For the bright future-bulk heterojunction polymer solar cells with power conversion efficiency of 7.4\%. Adv Mater 22:E135-E138

49. Zhao G, He Y, Li Y (2010) 6.5\% efficiency of polymer solar cells based on poly(3-hexylthiophene) and indene-C60 bisadduct by device optimization. Adv Mater 22:4355-4358

50. Zhou N, Kim M-G, Loser S, Smith J, Yoshida H, Guo X, et al. (2015) Amorphous oxide alloys as interfacial layers with broadly tunable electronic structures for organic photovoltaic cells. Proc Natl Acad Sci 112:7897-7902 